\title{
WEAR AND CORROSION STUDIES ON FERRITIC STAINLESS STEEL
}

\section{(SS 409M)}

\author{
P.S.Sampath ${ }^{1}$, V.Manimaran ${ }^{2}$, A.Gopinath ${ }^{3}$, M.M.Gobisankar ${ }^{4}$ \\ ${ }^{I}$ Department of Mechanical Engineering, K.S.Rangasamy College of Technology Tiruchengode, Namakkal, \\ Tamilnadu 637215, India \\ ${ }^{2}$ Department of Mechanical Engineering, K.S.Rangasamy College of Technology Tiruchengode, Namakkal, \\ Tamilnadu 637215, India \\ ${ }^{3}$ Department of Mechanical Engineering, K.S.Rangasamy College of Technology Tiruchengode, Namakkal, \\ Tamilnadu 637215, India \\ ${ }^{4}$ Department of Mechanical Engineering, K.S.Rangasamy College of Technology Tiruchengode, Namakkal, \\ Tamilnadu 637215, India
}

\begin{abstract}
The wear and corrosion behavior of SS 409M have been evaluated and compared with Mild steel ferritic stainless steel SS 430, and austenitic stainless steel SS 304. The SS 409M is a utility grade ferritic stainless steel, and has a very low Ni percentage less than $0.30 \%$. Annealed SS 409M contains ferrite and low percentage of tempered martensite whereas normalized SS 409M has low ferrite and higher percentage of tempered martensite. The manufacturing cost for this steel is low as compared to other grades of stainless steel but it has high strength with excellent corrosion resistance, abrasion resistance and can be easily fabricated. Thus SS 409M has been found to be a suitable material for replacing mild steel in structural applications. SS 409M has also got good wear resistance and this can be considered as an alternate material for mild steel in the railway wagons, track armor, and chemical tanks. The dry wear test has been carried out using the pin on disc machine for all the specimens. The results show that 409M has higher wear resistance as compared to mild steel and SS 430. The corrosion test has been carried out using the potentiostat for SS 409M both in annealed and in the normalized condition and the results are compared with SS 430 and SS 304. SS 304 and SS 430 stainless steels show excellent corrosion resistance while SS 409M both in annealed and in normalized condition reveal higher corrosion resistance than mild steel. Results are discussed with published work on these steels.
\end{abstract}

Keywords: SS 409M, SS 409M, SS 430, SS 304

\section{INTRODUCTION}

The steels which do not undergo rust or stain formation is known as stainless steel. Steels having chromium content more than $\sim 12 \% \mathrm{Cr}$, are referred to as stainless steel. For the formation of stable passive film $12 \%$ of chromium is required, this film forms spontaneously on its surfaces and protects it against corrosion. Higher amount of $\mathrm{Cr}$ strengthens the passive film and further helps in passivation. $\mathrm{Cr}$ is a strong ferrite stabilizer and it suppresses the ferriteaustenite phase transformation. Nickel favors the rate of formation of passive film. When $\mathrm{Ni}$ is added in sufficient quantity, it stabilizes the austenite phase. It imparts toughness, ductility and ease of weldability. Since $\mathrm{Ni}$ is expensive Steel Authority of India(SAIL) developed stainless steel called 409M with optimal level of $\mathrm{Ni}$ and $\mathrm{Cr}$ content. These elements provide necessary corrosion resistance and are less expensive when compared to other grades of stainless steel. Because of low cost and ease of fabrication, 409M steels find many structural applications in rail wagons and military hardware.SAIL(INDIA) has introduced $409 \mathrm{M}$ grades stainless steel. It was first used in coal handling area in thermal power plants. Since then for thermal plants 409M grades has been used extensively. It finds major applications in liner plate bunkers in various thermal power plants. The development of 409M, a utility grade ferritic stainless steel, has proven to be a major step forward in continuing battle against corrosion[1,2], With chromium content of $10.8-12.5 \%, 409 \mathrm{M}$ accounts for high strength, excellent corrosion resistance, abrasion resistance and weldability at lesser cost. The corrosion resistance of $409 \mathrm{M}$ in chemical and marine environment is much higher than that of mild steel. This means that structures manufactured using $409 \mathrm{M}$ have longer life than mild steel or alloy steel.

\subsection{Microstructure}

\subsubsection{Chemical Compositions of SS 409M, SS 430, and SS 304}

Table 1.1 Chemical compositions of SS 409M, SS 430, and

\begin{tabular}{|c|c|c|c|c|}
\hline \multicolumn{5}{|c|}{ SS 304} \\
\hline Elements & $\begin{array}{l}\text { 409M(Ann } \\
\text { ealed) } \\
(\%)\end{array}$ & $\begin{array}{l}409 \mathrm{M}( \\
\text { Normali } \\
\text { zed) } \\
(\%)\end{array}$ & $\begin{array}{l}\text { SS } 430 \\
(\%)\end{array}$ & $\begin{array}{l}\text { SS } \\
304 \\
(\%)\end{array}$ \\
\hline $\mathrm{C}(\max )$ & 0.018 & 0.025 & 0.055 & 0.035 \\
\hline $\operatorname{Mn}(\max )$ & 0.82 & 0.85 & 0.48 & 1.63 \\
\hline $\mathrm{Si}(\max )$ & 0.42 & 0.59 & 0.40 & 0.47 \\
\hline
\end{tabular}




\begin{tabular}{|l|l|l|l|l|}
\hline $\mathrm{S}(\max )$ & 0.014 & 0.015 & 0.007 & 0.010 \\
\hline $\mathrm{P}(\max )$ & 0.030 & 0.024 & 0.0034 & 0.030 \\
\hline $\mathrm{Cr}$ & 11.12 & 11.35 & 16.36 & 17.62 \\
\hline $\mathrm{Ni}$ & 0.30 & 0.40 & 0.11 & 8.02 \\
\hline $\mathrm{N}(\max )$ & 0.017 & 0.020 & 0.027 & 0.065 \\
\hline
\end{tabular}

Materials obtained from Steel Authority of India Limited, Salem steel plant (INDIA) were in the form of rolled coil. In 409M (Annealed and normalized) there is slight variation of composition in ferritic stainless steel since it is obtained from two different coils.

\subsubsection{Optical Microscopy}

Samples of 409M (both annealed and normalized), SS 430, SS 304 and mild steel were chosen for microstructure studies. Metallography specimens[3], were cut using EDM machine. The extracted specimens were prepared by following the standard metallographic procedure discussed below.

(1) Grinding: Rough Grinding is done with belt grinder to improve the flatness of the sample. The rough grinding is continued until the surface is flat and free of nicks, burrs, and scratches due to hacksaw or cut of wheel.

(2) Intermediate Polishing: Polishing is done to remove scratches from the surface of the specimen. The sample is polished on series of emery papers containing finer abrasives like 120, 240, 400, 500, 800 grit papers. Intermediate Polishing operations using emery paper are usually done dry. The specimen is rotated progressively by $90^{\circ}$ between successive polishing in emery paper.

(3) Disc polishing: Disc polishing is further done to make the surface totally scratch free and to impart mirror finish. It is polished with diamond abrasive of $9 \mu, 1 \mu$ and $1 / 2 \mu$ charge cloth with diamond paste. The specimen is then cleaned using acetone and dried using a hot air dryer. Now the specimen is viewed in the microscope to confirm the surface finish and re-polishing is done if necessary. The finished mounts are preserved carefully for viewing the micrographs.

(4) Etching: The purpose of etching is to make visible the structural characteristics of this steel. The etching process must be such that different phases of the microstructure may be clearly differentiated. This is accomplished by the use of an appropriate reagent which subjects the polished surface to preferential chemical attack. Etchant is applied on the surface of the specimen to reveal the grain boundaries. The specimens were etched using Aqua regia.

\subsubsection{Etching Details}

The etchants used are Aqua regia, Nitric Acid (30ml), Hydrochloric acid (70ml). The etching time takes about 1015 seconds.After etching the specimen is cleaned immediately in running water followed by swabbing with acetone. Then it is dried under infra red lamp for few minutes[4].After preparing the metallographic specimen, the specimen is observed under Leica make optical microscope at different magnifications such as 100X, 200X and 500X.

\subsection{Wear Characterization}

The experimental procedure used for studying the dry sliding wear was done using pin on disc apparatus.

\subsubsection{Specimen Preparation}

The wear specimens of dimensions $(10 \mathrm{mmX} 10 \mathrm{mmX} 8 \mathrm{~mm})$ were cut in the EDM machine. Since minimum height requirement is $40 \mathrm{~mm}$, wear specimen is attached with the mild steel rod to match this $40 \mathrm{~mm}$ height. The grinding of end faces of the pins is done using emery papers of five different grades 220, 400,600, 800 and 1000 in the same order .Grinding was followed by polishing with 1/0, 2/0, 3/0 and $4 / 0$ grades polishing papers.

\subsubsection{Experimental Set Up}

Dry sliding wear tests for the SS409M cylindrical specimens were conducted using a pin- on -disc machine(Wear and Friction Monitor Tester TR-201made by M/S DUCOM, Bangalore, INDIA) conforming to ASTM G 99 standard. Wear tests were performed on the pin specimens that has flat surfaces in the contact regions and the rounded corner. The pin was held stationery against the counter face of a rotating disc made of carbon steel (EN-31) at minimum of $50 \mathrm{~mm}$ diameter and a maximum of $100 \mathrm{~mm}$ diameter. The composition of the material of the steel disc is given in Table 2.2.

Table 1.2 Chemical composition (wt \%) of the En-31 carbon steel disc

\begin{tabular}{|l|l|l|l|l|}
\hline $\mathrm{C}$ & $\mathrm{Si}$ & $\mathrm{Mn}$ & $\mathrm{S}$ & $\mathrm{P}$ \\
\hline 0.42 & $0.05-$ & $0.40-$ & $0.05(\max$ & 0.05 \\
$(\max )$ & 0.35 & 0.70 & ) & $(\max )$ \\
\hline
\end{tabular}

A pin- on -disc machine was used to investigate the dry sliding wear characteristics of the SS 409M samples as per ASTM G99 standard. Both the pin and the counter face were cleaned with acetone before experimentation. The experiments were conducted to study the effect of sliding speed, applied load, sliding distance on wear behavior of SS $409 \mathrm{M}$. The tests were conducted with the load ranging from $2 \mathrm{~kg}$ to $4 \mathrm{~kg}$ at different sliding speed and different sliding distances were considered at constant sliding speed and applied load. All these tests were conducted at room temperature.During the test, the pin was pressed against the counterpart rotating against an EN 32 steel disc having hardness of $65 \mathrm{HRc}$ by applying load. After running through a fixed sliding distance, the specimen were removed, cleaned with acetone, dried and weighed to determine the weight loss due to wear. The difference in the weight measured before and after test gives the wear of the specimen. The wear of the stainless steel was studied as a function of the volume percentage, sliding distance, applied load and the sliding velocity.

\subsubsection{Wear Rate}

The wear rate data for the coated as well as uncoated specimens were plotted with respect to sliding distance to establish the wear kinetics. The specific wear rates for the 
coated and uncoated material were obtained by $\mathrm{W}=\delta \mathrm{w} /$ $\mathrm{L} \rho \mathrm{F}$ where $\mathrm{W}$ denotes specific wear rates in Bowden (B) $\left(1 \mathrm{~B}=10^{-6} \mathrm{~mm}^{3} / \mathrm{N}-\mathrm{m}\right)$ [Recommendation from IRG OECD meeting with about 30 participants to introduce a new unit for wear rate: Bowden (B) equal to $\left.10-6 \mathrm{~mm}^{3} / \mathrm{N} . \mathrm{m}\right], \delta$ wis the weight loss measured in $\mathrm{g}, \mathrm{L}$ is the sliding distance in $\mathrm{m}, \rho$ the density of the worn material in $\mathrm{g} / \mathrm{mm}^{3}$ and $\mathrm{F}$ the applied load in N[5].

\subsubsection{Wear Volume}

The wear volume loss was also calculated from the weight loss and density of the coatings as well as substrate material for all the investigated cases. These data were reported in the form of plots showing the cumulative wear volume loss Vs sliding distance for all the cases. Bar charts were also drawn to show net Volume $=$ mass $/$ density.

$$
\text { Wear Volume Loss }=(\delta \mathrm{w} / 9.81) / \rho
$$

where $\delta \mathrm{w}$ is the weight loss in, $\mathrm{g}$ $\rho$ is the density of material, $\mathrm{g} / \mathrm{mm}^{3}$

\subsubsection{Coefficient Of Friction}

The coefficient of friction $(\mu)$ determined from the frictional force and the normal load has been plotted against the sliding time to give the friction behavior of the coated as well as the uncoated material. The coefficient of friction $(\mu)$ was calculated as below: $\mu=$ Frictional Force (N) / Applied Normal Load(N).

\subsection{Corrosion Test}

Mild steel, SS 409M, SS 430 and SS 304 of dimension $10 \mathrm{~mm} \times 10 \mathrm{~mm} \times 8 \mathrm{~mm}$ were used to study the corrosion in 3 wt $\% \mathrm{NaCl}$ solution. The samples were polished successively using emery sheets of 120, 320, 1000 and 2000 grades and then cleaned with acetone. Polarization tests were carried out using potentiostat of model Gamry600 framework using an inbuilt Echem software corrosion rate and current values obtained. Electrochemical impedance spectroscopy is used to analyse the corrosion in $3 \mathrm{wt} \%$ $\mathrm{NaCl}$ solution further. This test was carried out at open circuit potential. Nyquist and Bode plot was obtained from this test.

\subsection{Scanning Electron Microscopy (SEM)}

The SEM provides the highly magnified image of the surface of the material. The resolution of the SEM can approach a few $\mathrm{nm}$ and it can operate at magnifications that are easily adjusted from 10 to $100000 \mathrm{X}$. The specimens after the wear and corrosion test were cleaned with acetone and then dried. SEM characterization was done at $25 \mathrm{kV}$ accelerating voltage[6,7],Samples were loaded on the specimen table in the SEM chamber and the necessary vacuum was created using rotary and mechanical pumps. SEM micrographs were taken for all the samples after wear and corrosion test at different magnifications such as $100 \mathrm{x}$, 200x and 500x in secondary electron (SE) mode.

\section{RESULTS AND DISCUSSION}

\subsection{Optical Microscope Results}

The microstructure of the specimens using optical microscope is shown in the Figure 3.1 Microstructure of mild steel which has ferrite and pearlite structures, in the Figure 3.2 Microstructure of 409M (Annealed) hasferrite and low tempered martensite, in the Figure 3.3 Microstructure of SS 409M (Normalized) has ferrite and more tempered martensite when compare with 409M (Annealed), in the Figure 3.4 Microstructure of SS 430 as an ferritic stainless steel has ferrite structure, in the Figure 3.5 Microstructure of SS 304 is an austenitic stainless steel has twine structure.

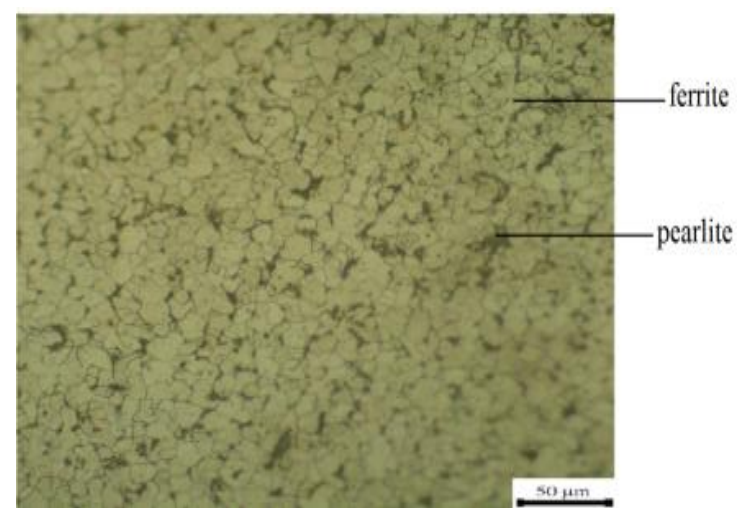

Fig3.1 Microstructure of mild steel

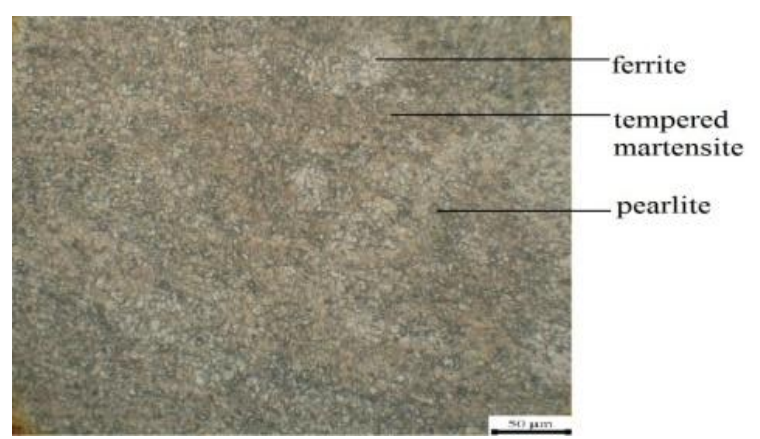

Fig3.2 Microstructure of 409M (Annealed)

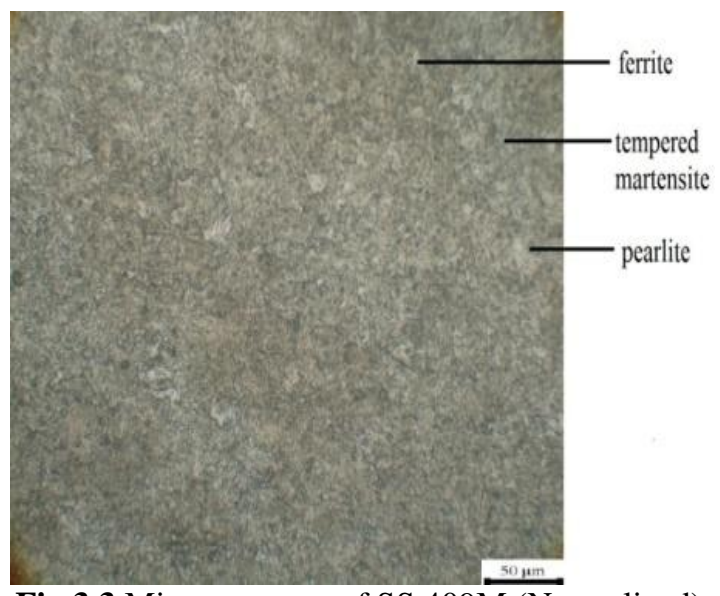

Fig 3.3 Microstructure of SS 409 $\overline{\mathrm{M} \text { (Normalized) }}$ 


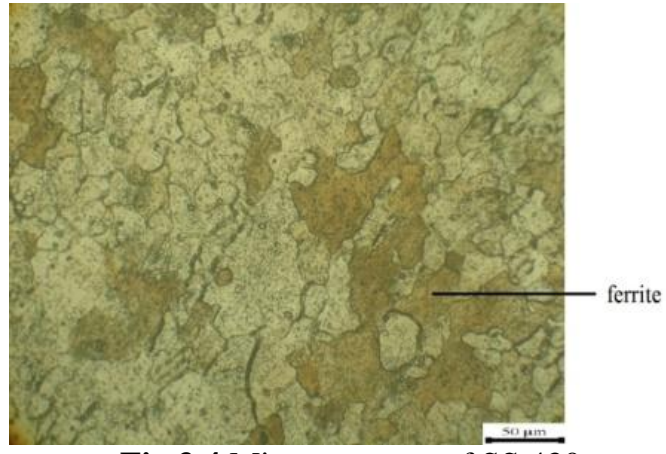

Fig 3.4 Microstructure of SS 430

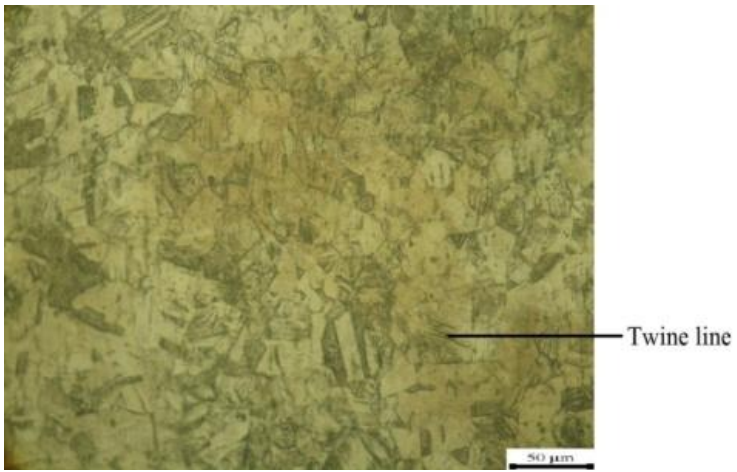

Fig 3.5Microstructure of SS 304

\subsection{Wear Behaviour}

The wear test for 409M (Annealed and Normalized), mild steel, SS 430 and SS 304 are carried out usingPin On Disc machine. The test was conducted using $2 \mathrm{~kg}, 3 \mathrm{~kg}, 4 \mathrm{~kg}$ at a speed of $500 \mathrm{rpm}$ for 10, 15and 20 minutes of time period respectively[8]The wear rate and volume of mild steel for different loads and at various times are given in the Figure 3.1.Figure3.2 gives the result for SS $409 \mathrm{M}$ (Annealed), Figure 3.3 for SS (Normalized), Figure3.4 provides the results for SS 430 steel and Figure 3.5 provides the results for SS 304.

\subsubsection{The Variations of Wear Volume Loss with} Sliding Distance at $2 \mathrm{~kg}, 3 \mathrm{~kg}$ and $4 \mathrm{~kg}$ load for Different Steels are shown in Figure 3.1, Figure3.2 and Figure 3.3 respectively.

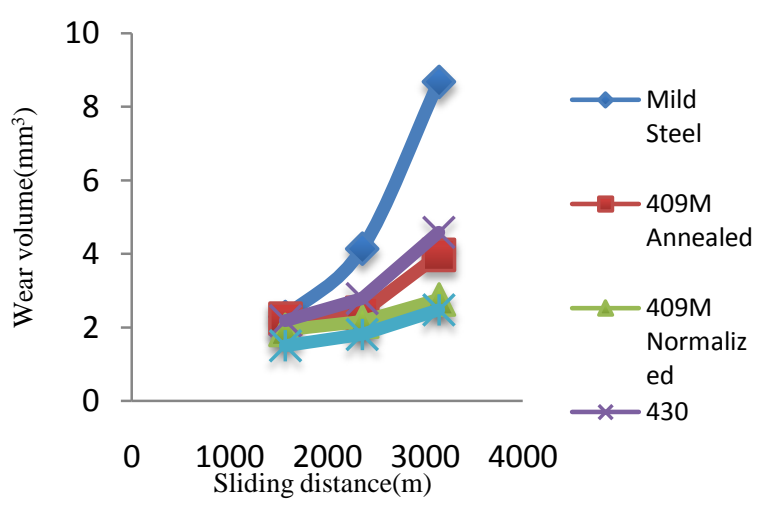

Fig 3.1 Variations of wear volume loss Vs sliding distance at $2 \mathrm{Kg}$ load
The higher wear volume of mild steel, SS 409M (Annealed), SS $409 \mathrm{M}$ (Normalized), SS 430 and SS 304 at $2 \mathrm{~kg}$ load for 20 minutes is $8.6798 \mathrm{~mm}^{3}, 3.9743 \mathrm{~mm}^{3}, 2.7650 \mathrm{~mm}^{3}, 4.5913$ $\mathrm{mm}^{3}$ and $2.4767 \mathrm{~mm}^{3}$ respectively. Mild steel has higher wear volume loss which result in lower wear resistance. SS 409M (Annealed) and SS 409M(Normalized) has lower wear volume loss compared with mild steel and SS 430. In comparison with all these materials SS 304 has lower wear volume loss which results in superior wear resistance

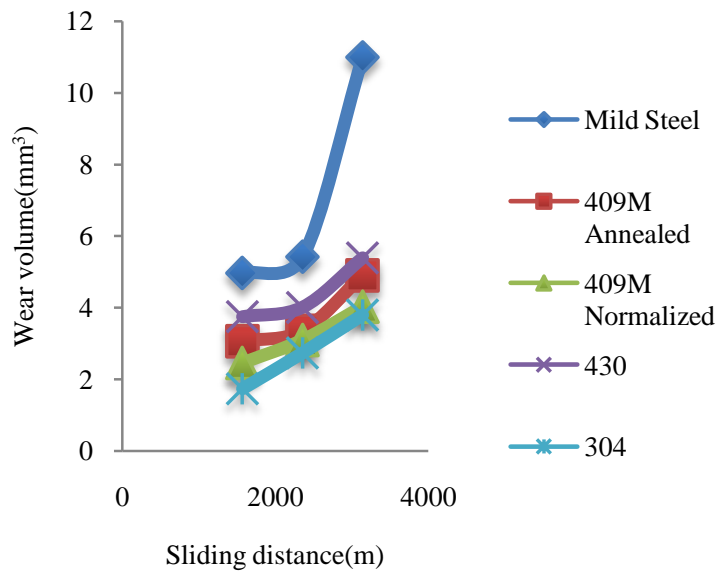

Fig 3.2 Variations of wear volume loss Vs sliding distance at $3 \mathrm{Kg}$ load

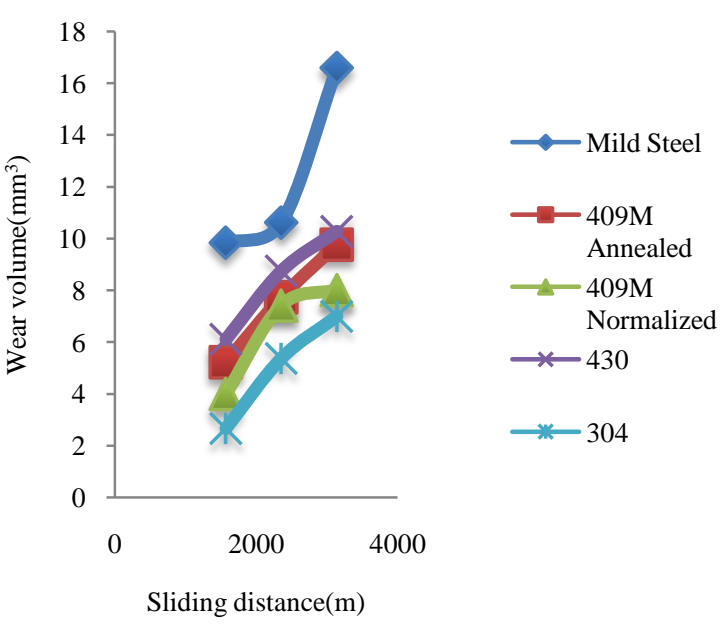

Fig 3.3 Variations of wear volume loss Vs sliding distance at $4 \mathrm{Kg}$ load

The higher wear volume of mild steel, SS 409M (Annealed), SS 409M(Normalized), SS 430 and SS 304 at $4 \mathrm{~kg}$ load for 20 minutes is $16.5870 \mathrm{~mm}^{3}, 9.7692 \mathrm{~mm}^{3}, 8.0172 \mathrm{~mm}^{3}$, $10.2800 \mathrm{~mm}^{3}$ and $6.9960 \mathrm{~mm}^{3}$ respectively. Mild steel has higher wear volume loss, which result in lower wear resistance. SS 409M (Annealed) and SS 409M(Normalized) have lower wear volume loss compare with Mild steel and SS 430. When wear loss is compare with $409 \mathrm{M}$ (Annealed and Normalized) 409M Normalized have lowerwear loss. Compare with all these materials SS 304 has lower wear volume loss, which results in superior wear resistance. 
3.2.2 The variation of Wear Rate with Load at a Sliding Distance of $1570.80 \mathrm{~m}, 2356.19 \mathrm{~m}$ and 3141.59m for Different Materials are shown in the

\section{Figure 3.4, Figure 3.5 and Figure 3.6 respectively.}

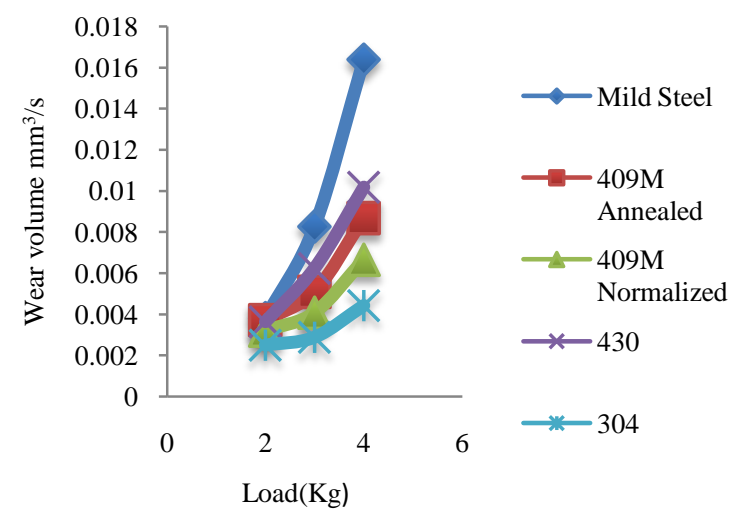

Fig 3.4 Variations of wear rate Vs load at sliding distance of $1570.80 \mathrm{~m}$

The higher wear rate of mild steel, SS 409M (Annealed), SS 409M(Normalized), SS 430 and SS 304 at $1570.80 \mathrm{~m}$ travel distance for $4 \mathrm{~kg}$ load is $0.0163980 \mathrm{~mm}^{3} / \mathrm{s}, 0.0407 \mathrm{~mm}^{3} / \mathrm{s}$, $0.006671 \mathrm{~mm}^{3} / \mathrm{s}, 0.010190 \mathrm{~mm}^{3} / \mathrm{s}$ and $0.004400 \mathrm{~mm}^{3} / \mathrm{s}$ respectively. Mild steel has higher wear rate which results in lower wear resistance. SS 409M (Annealed) and SS 409M(Normalized) have lower wear rate compare with Mild steel and SS 430. When wear rate is compared with 409M (Annealed and Normalized) 409M Normalized have lower wear rate. In comparison with all these materials SS 304 has lower wear rate which results in superior wear resistance.

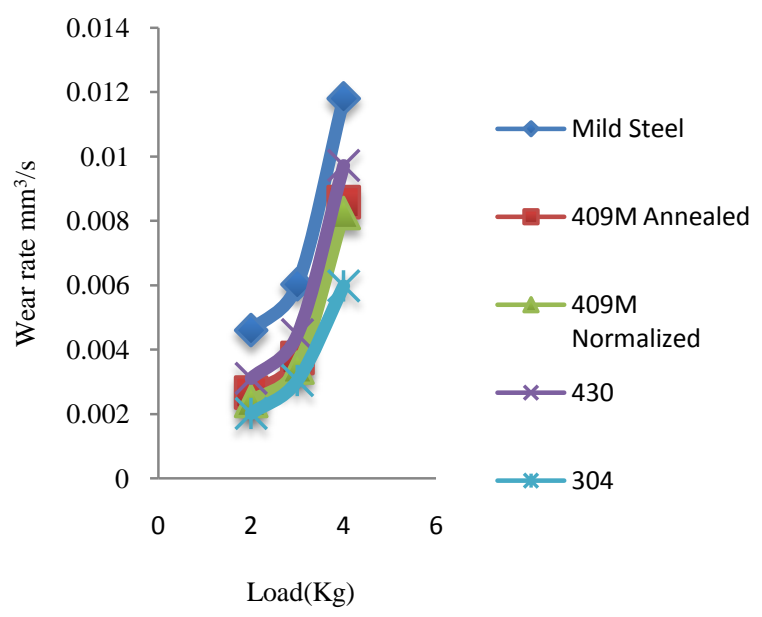

Fig 3.5 Variations of wear rate Vs load at sliding distance of $2356.19 \mathrm{~m}$

The higher wear rate of mild steel, SS 409M (Annealed), SS $409 \mathrm{M}$ (Normalized), SS 430 and SS 304 at 2356.19m travel distance for $4 \mathrm{~kg}$ load is $0.0118000 \mathrm{~mm}^{3} / \mathrm{s}, 0.0085800$ $\mathrm{mm}^{3} / \mathrm{s}, 0.008242 \mathrm{~mm}^{3} / \mathrm{s}, 0.0097263 \mathrm{~mm}^{3} / \mathrm{s}$ and 0.005971 $\mathrm{mm}^{3} / \mathrm{s}$ respectively. Mild steel has higher wear rate, which result in lower wear resistance. SS 409M (Annealed) and SS 409M(Normalized) have lower wear rate compare with Mild steel and SS 430. When wear rate is compare with 409M(Annealed and Normalized) 409M Normalized have lower wear rate. In comparison with all these materials SS 304 has lower wear rate, which results in superior wear resistance.

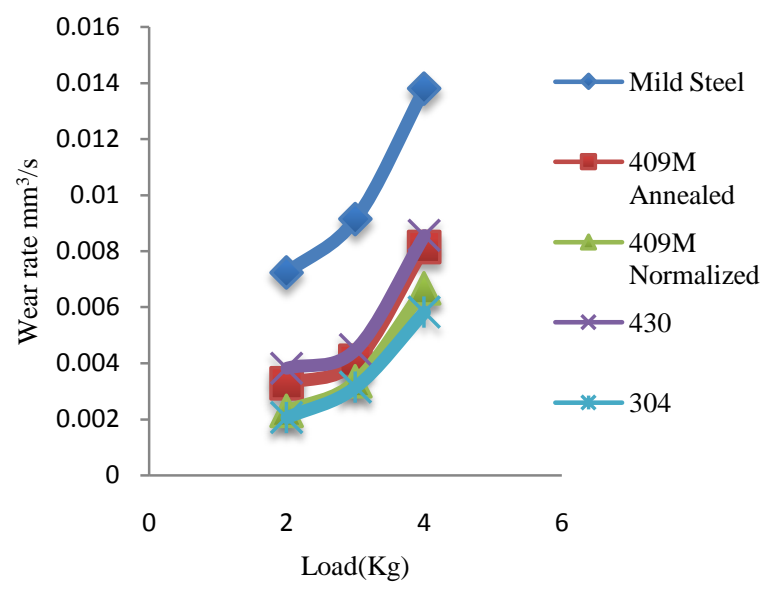

Fig 3.6 Variations of wear rate with load at sliding distance of $3141.59 \mathrm{~m}$

The higher wear rate of mild steel, SS 409M (Annealed), SS 409M(Normalized), SS 430 and SS 304 at $3141.51 \mathrm{~m}$ travel distance for $4 \mathrm{~kg}$ load is $0.013160 \mathrm{~mm}^{3} / \mathrm{s}, 0.0081420 \mathrm{~mm}^{3} / \mathrm{s}$, $0.006681 \mathrm{~mm}^{3} / \mathrm{s}, 0.0085667 \mathrm{~mm}^{3} / \mathrm{s}$ and $0.005830 \mathrm{~mm}^{3} / \mathrm{s}$ respectively. Mild steel has higher wear rate, which result in lower wear resistance. SS 409M (Annealed) and SS 409M(Normalized) have lower wear rate compare with Mild steel and SS 430. Whenwear rate is compare with 409M(Annealed and Normalized) 409M Normalized have lower wear rate in In comparisonwith all these materials SS 304 has lower wear rate, which results in superior wear resistance.

\subsection{SEM Images after Wear Test}

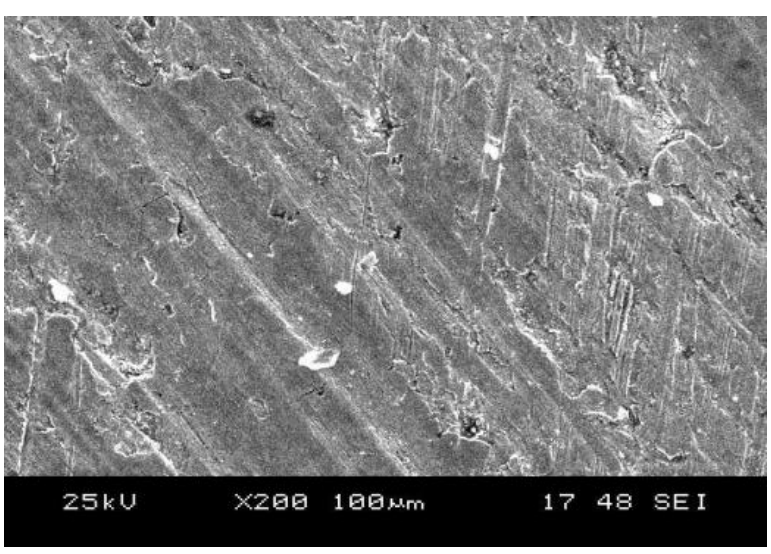

Fig3.7 SEM Image of Mild Steel after Wear test

The SEM Image of Mild Steel after wear test at $4 \mathrm{~kg}$ load at a speed of 500rpm and for 20 minutes time period is shown in the Figure 3.7. Wear track formation on the surface can be seen. 


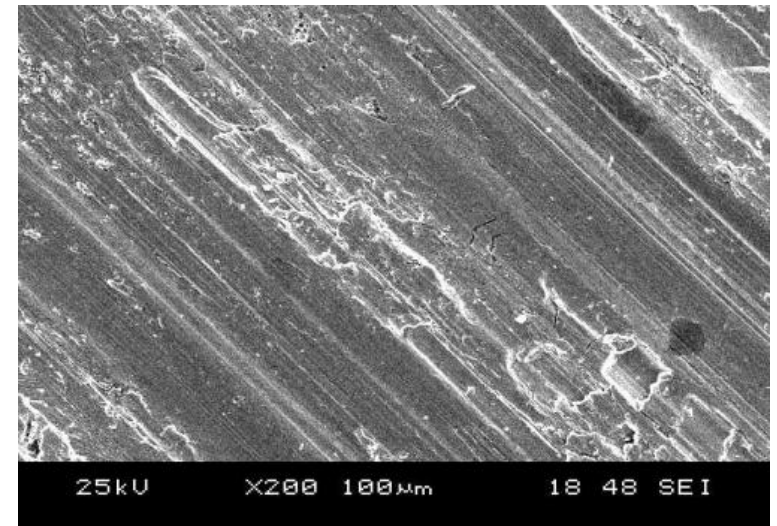

Fig 3.8 SEM Image of 409M (Annealed) after Wear test

The SEM Image of 409M (Annealed) after wear test at $4 \mathrm{~kg}$ load, speed of 500rpm and for 20 minutes time period is shown in the Figure 3.8. Uniform wear track formation on the surface can be seen.

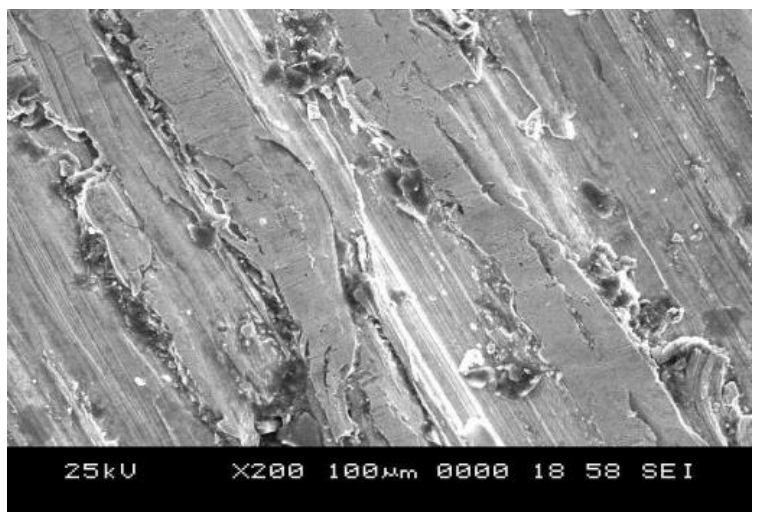

Fig 3.9 SEM Image of 409M (Normalized) after Wear test

The SEM Image of 409M (Normalized) after wear test at 4 $\mathrm{kg}$ load, speed of 500rpm and for 20 minutes time period is shown in the Figure 3.9. Wear track formation on the surface can be seen.

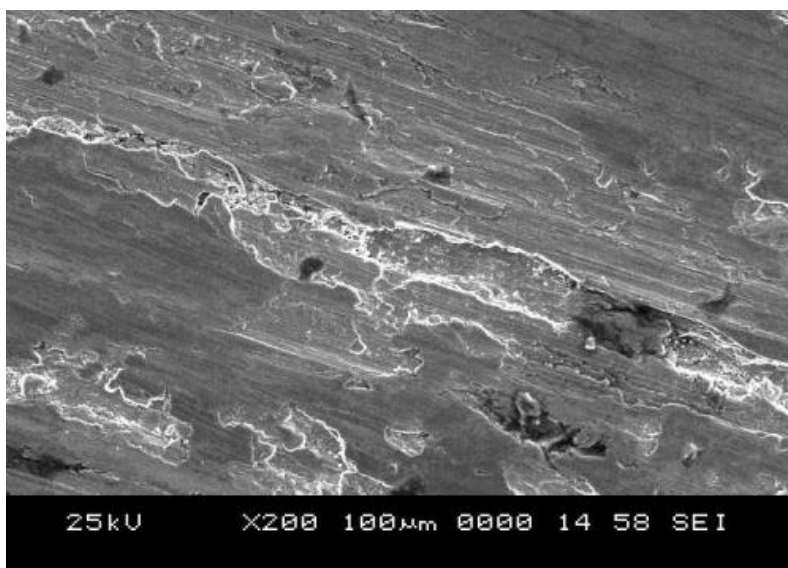

Fig3.10 SEM Image of 430 after Wear test

The SEM Image of 430 after wear test at $4 \mathrm{~kg}$ load, speed of $500 \mathrm{rpm}$ and for 20 minutes time period is shown in the Figure 3.10. Wear track formation on the surface can be seen.

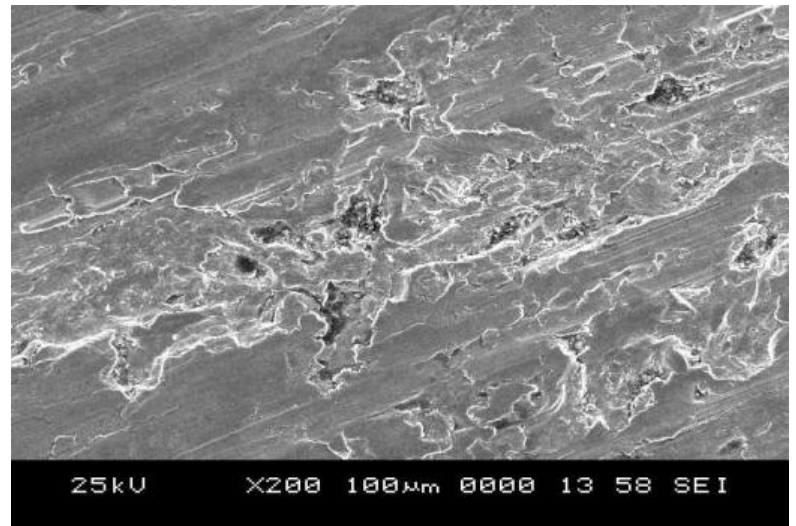

Fig3.11 SEM Image of 304 after Wear test

The SEM Image of 304 after wear test at $4 \mathrm{~kg}$ load, speed of 500rpm and for 20 minutes time period is shown in Figure 3.16. Wear track formation on the surface can be seen.

\subsection{Corrosion Test}

The corrosion test for409M (Annealed and Normalized), mild steel, SS 430 and SS 304 is carried out using Potentiostat in $3 \mathrm{wt} \%$ of $\mathrm{NaCl}$ solution. Polarization curve is generated using Gamry600 framework using inbuilt Echem software. This was carried out in open circuit potential[9]

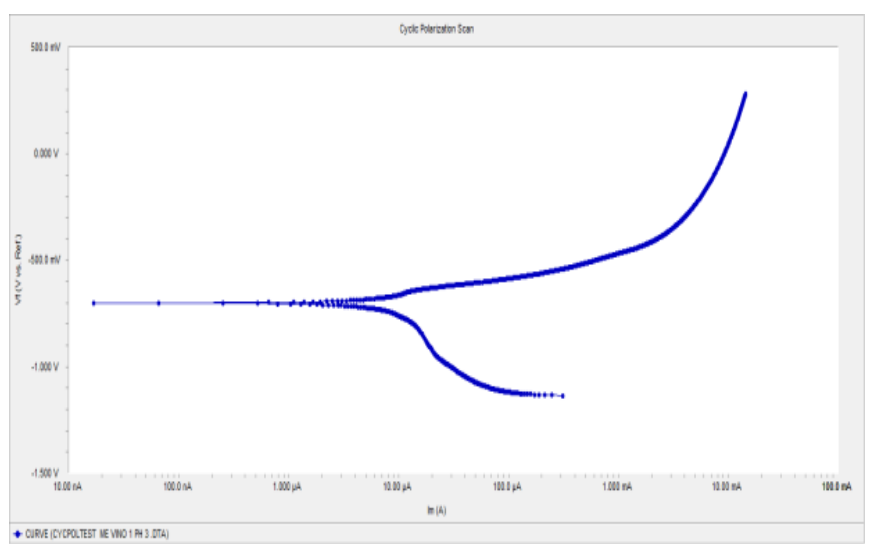

Fig 3.11 Polarization curve of Mild steel

The Polarization curve of Mild steel is shown in Figure 3.17. In this curve mild steel does not exhibit passivation, only dissolution of electrons takes place.

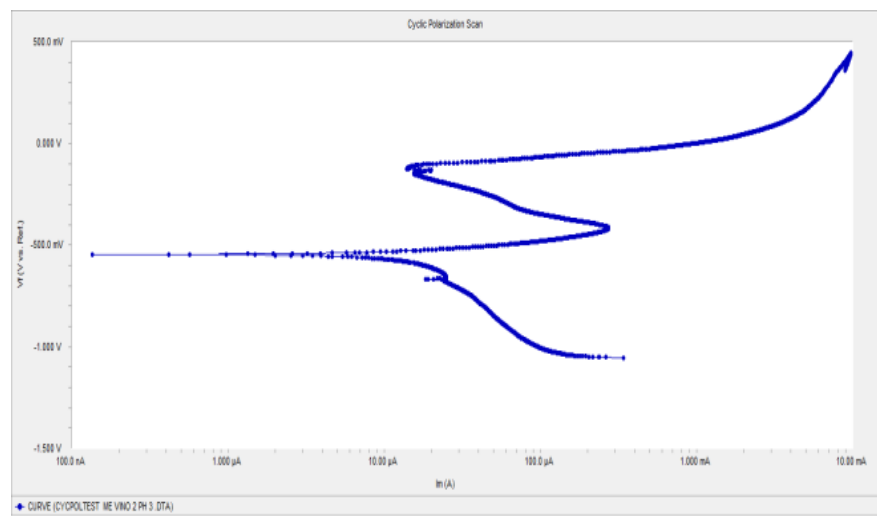

Fig 3.12 Polarization curve of SS 409M (Annealed) 
ThePolarization curve of SS 409M (Annealed) is shown in the Figure 3.12. In this curve SS 409M (Annealed) exhibits passivation from $(-400 \mathrm{mV}$ to $-50 \mathrm{mV})$.

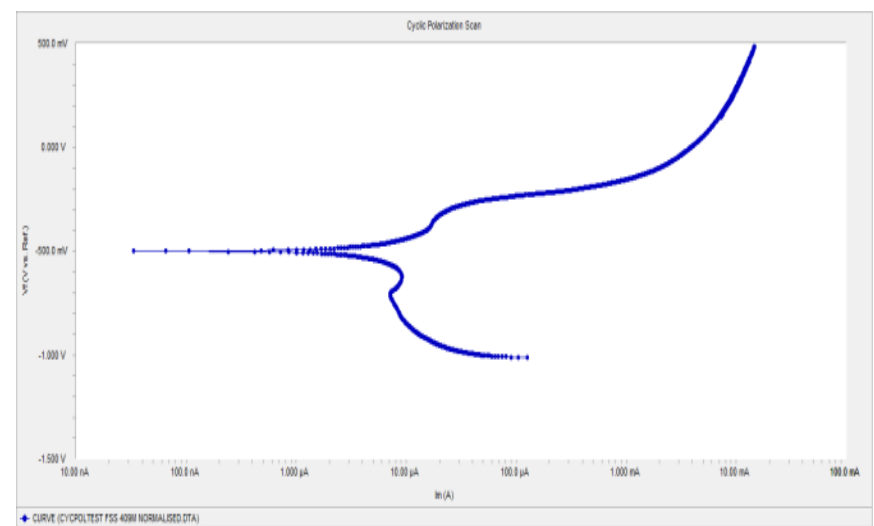

Fig 3.13 Polarization curve of SS 409M (Normalized)

The Polarization curve of SS 409M (Normalized) is shown in Figure 3.19, in this curve SS 409M (Normalized) exhibits less passivation.

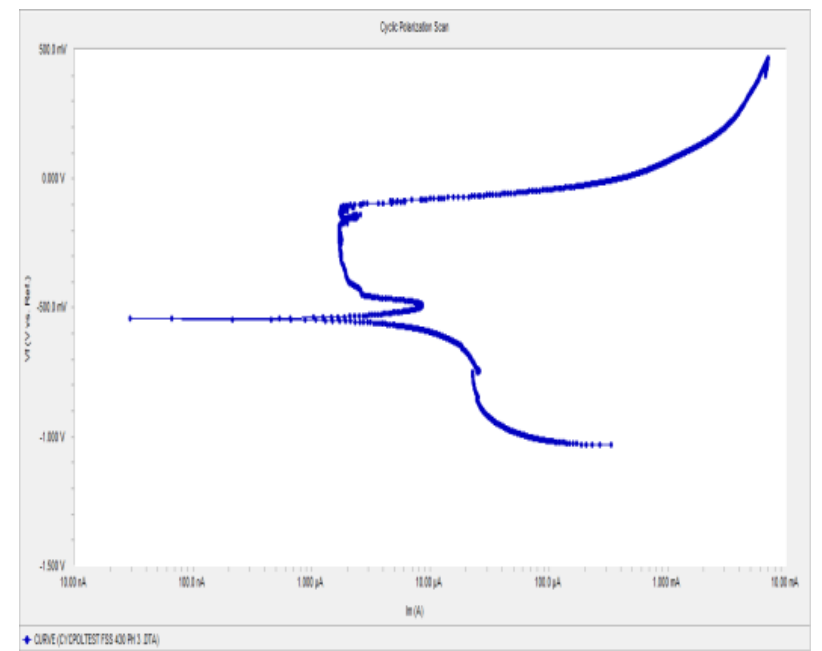

Fig 3.14 Polarization curve of SS 430

The Polarization curve of SS 430 is shown in the Figure 3.20. In this curve SS 430 exhibits passivation from ($500 \mathrm{mV}$ to $0.00 \mathrm{mV}$ ).

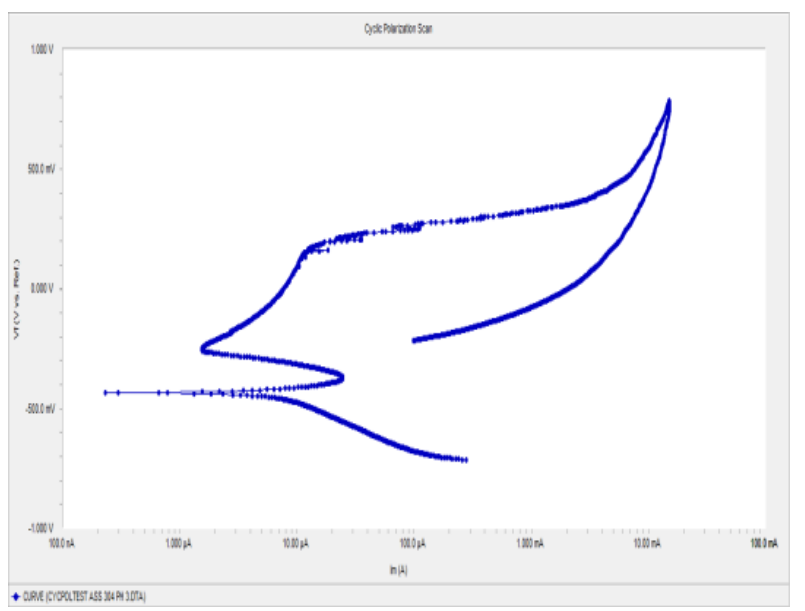

Fig 3.15 Polarization curve of SS 304
The Polarization curve of SS 304 is shown in Figure 3.15. In this curve SS 304 exhibits passivation from $(-250 \mathrm{mV}$ to $250 \mathrm{mV})$.

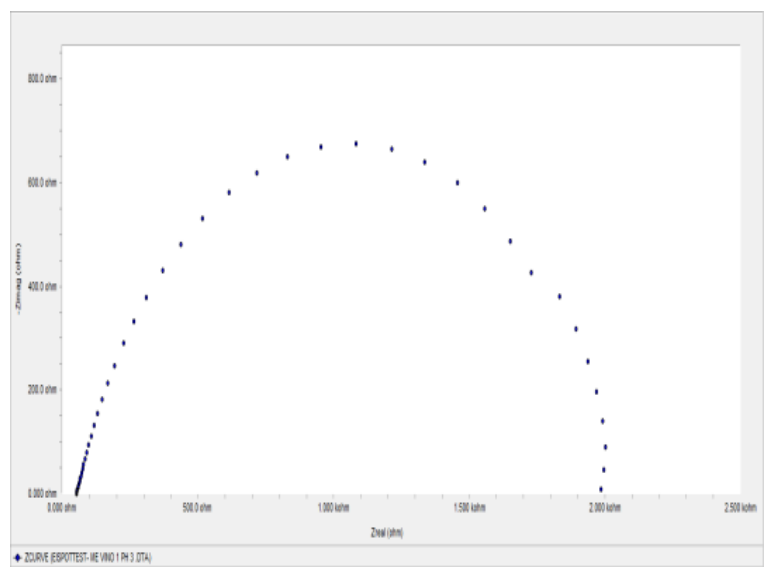

Fig 3.16 NYQUIST PLOT for Mild steel

The NYQUIST PLOT for Mild steel is shown in Figure 3.16. In this curve Mild steel exhibit the $\mathrm{R}$ polarization values of $2 \mathrm{kohm}$. This results in lower corrosion resistance.

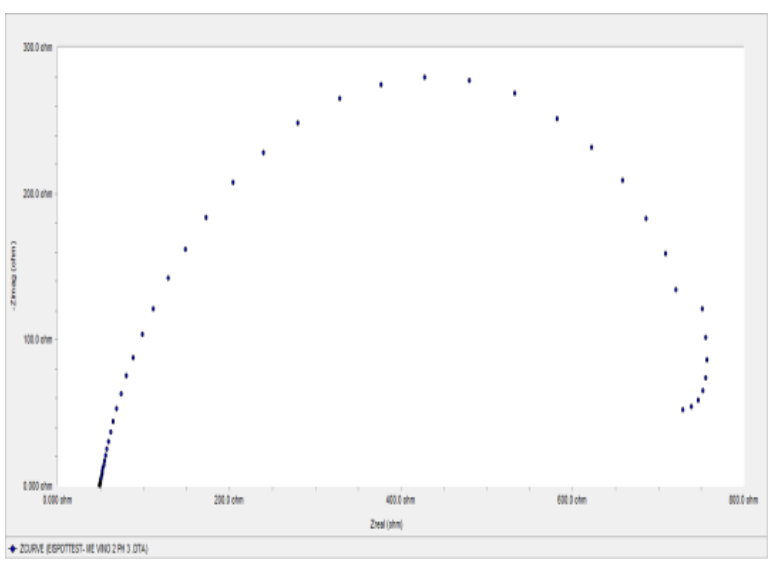

Fig 3.17 NYQUIST PLOT for SS 409M (Annealed)

The NYQUIST PLOT for SS 409M (Annealed) is shown in Figure 3.17. In this curve SS 409M (Annealed) exhibits the $\mathrm{R}$ polarization values of $8 \mathrm{kohm}$. This results in higher corrosion resistance than mild steel.

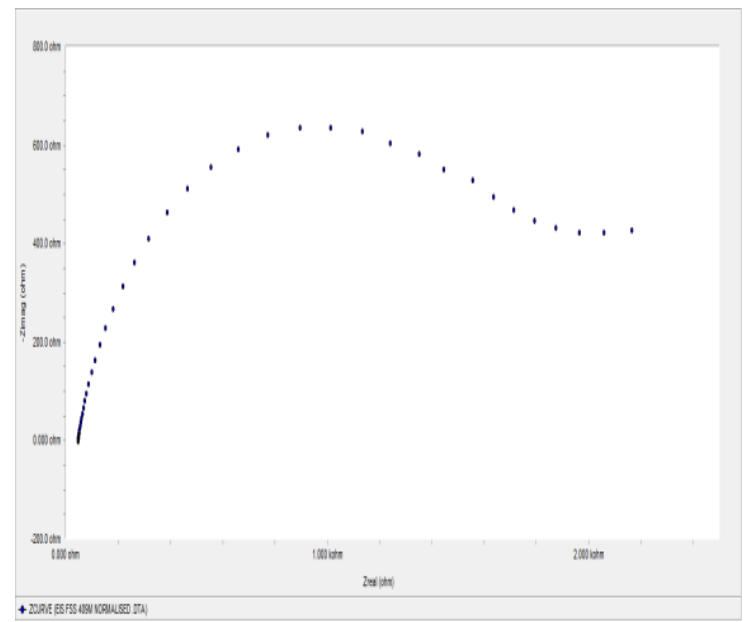

Fig 3.18 NYQUIST PLOT for SS 409M (Normalized) 
The NYQUIST PLOT for SS 409M (Normalized) is shown in Figure 3.18. In this curve SS 409M (Annealed) exhibits the $\mathrm{R}$ polarization values ends at some infinite point. This results in higher corrosion resistance.

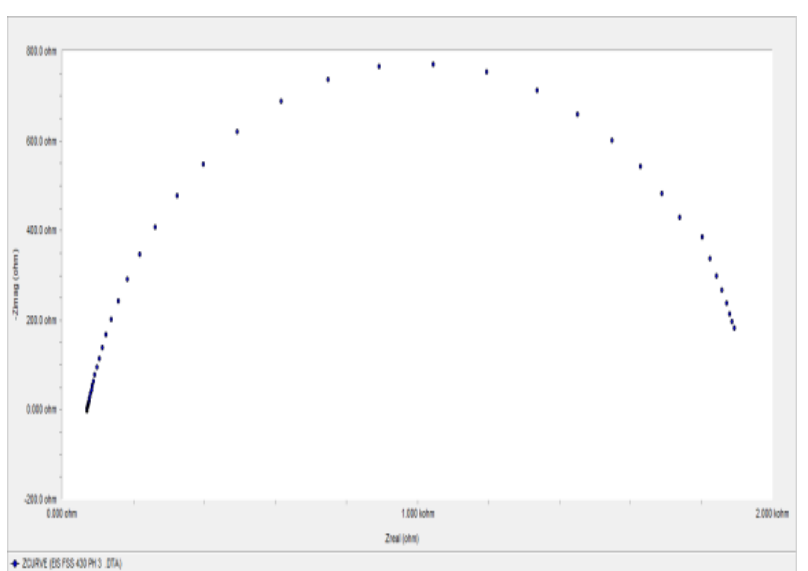

Fig3.19 NYQUIST PLOT for SS 430

The NYQUIST PLOT for SS 430 is shown in Figure 3.19. In this curve SS 430 exhibits the $\mathrm{R}$ polarization values ends at some infinite point. This results in higher corrosion resistance when compared with mild steel, SS 409M (Annealed), and SS 409M (Normalized).

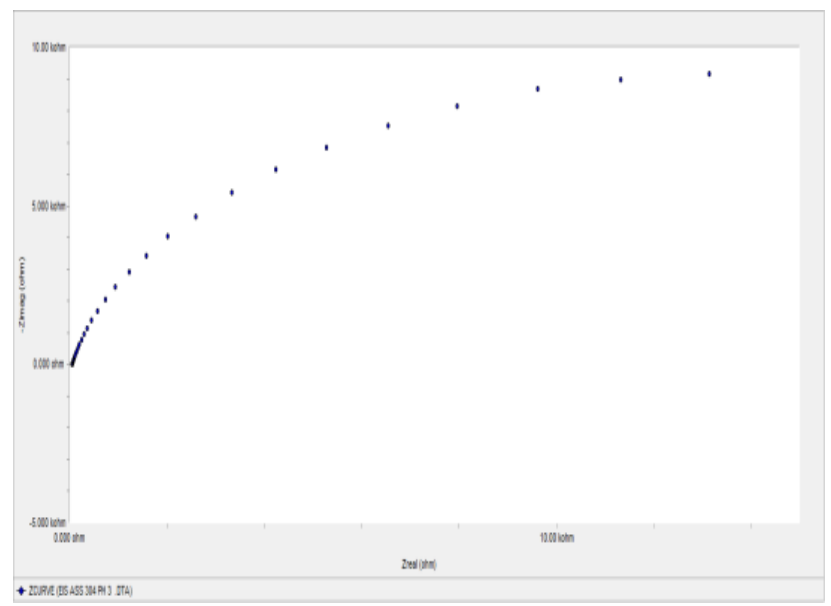

Fig 3.20 NYQUIST PLOT for SS 304

The NYQUIST PLOT for SS 304 is shown in Figure 3.26. In this curve SS 304 exhibits the R polarization values ends at some infinite point. This results in higher corrosion resistance when compared with mild steel, SS 409M (Annealed), SS 409M (Normalized) and SS 304.

\subsubsection{Electrochemical Tests carried out using 3 pH NaCl Solution}

Table 3.21 Result of electrochemical test in 3 wt $\%$ of $\mathrm{NaCl}$ solution

\begin{tabular}{|c|c|c|c|}
\hline Material & $\begin{array}{c}\text { icorr } \\
\left(\mu \mathrm{A} / \mathrm{cm}^{2}\right. \\
)\end{array}$ & $\begin{array}{c}\text { Ecorr } \\
(\mathrm{mV})\end{array}$ & $\begin{array}{c}\text { Corrosion } \\
\text { Rate }(\mathrm{mpy})\end{array}$ \\
\hline Mild Steel & 25.60 & -701.0 & 19.72 \\
\hline SS 409M & 13.20 & -545.0 & 8.031 \\
\hline
\end{tabular}

\begin{tabular}{|c|c|c|c|}
\hline (Annealed) & & & \\
\hline $\begin{array}{c}\text { SS 409M } \\
\text { (Normalized) }\end{array}$ & 15.80 & -498.0 & 11.42 \\
\hline SS 430 & 7.860 & -433.0 & 4.727 \\
\hline SS 304 & 1.890 & -543.0 & 1.646 \\
\hline
\end{tabular}

The corrosion rate of SS 409M in annealed and normalized is $8.031 \mathrm{mpy}$ and $11.42 \mathrm{mpy}$ respectively. From these values 409M (Annealed) has lower corrosion rate than 409M (Normalized). SS 409M has lower corrosion rate than mild steel. The corrosion rate of SS 304 is $1.66 \mathrm{mpy}$ which shows superior corrosion resistance than all the materials.

\subsubsection{SEM Images after Corrosion Test}

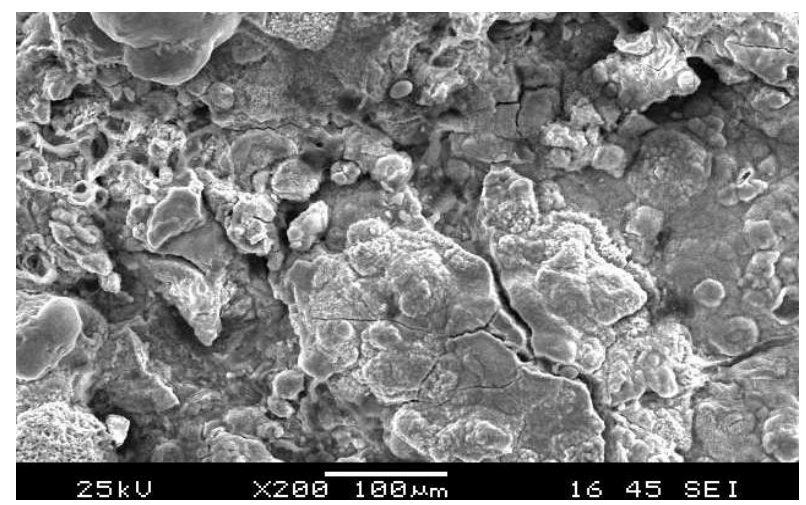

Fig 3.21 SEM Image of Mild Steel after corrosion test

The SEM Image of Mild Steel after corrosion test is shown in the Figure 3.21. We could also seethe cracks along the grain boundaries that result in poor corrosion resistance.

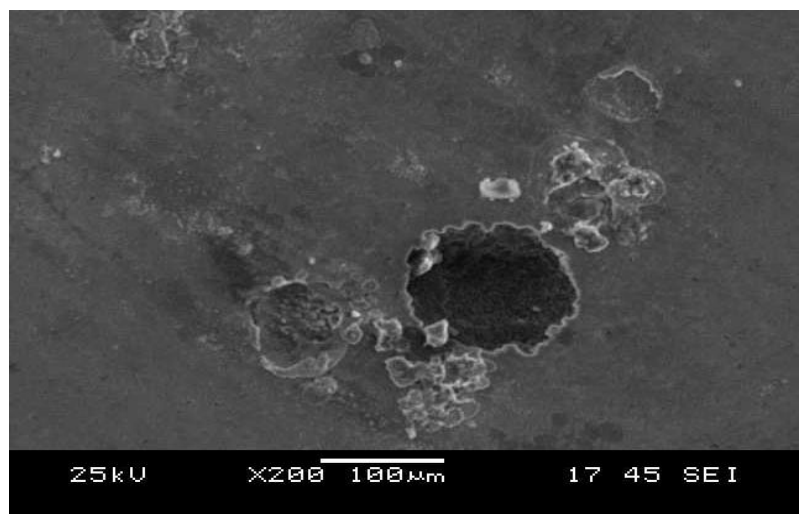

Fig 3.22 SEM Image of 409M (Annealed) after corrosion test

The SEM Image of 409M (Annealed) after corrosion test is shown in Figure 3.22. The image indicates the pit formation clearly, we could also see the dissolutions surrounding the pit. 


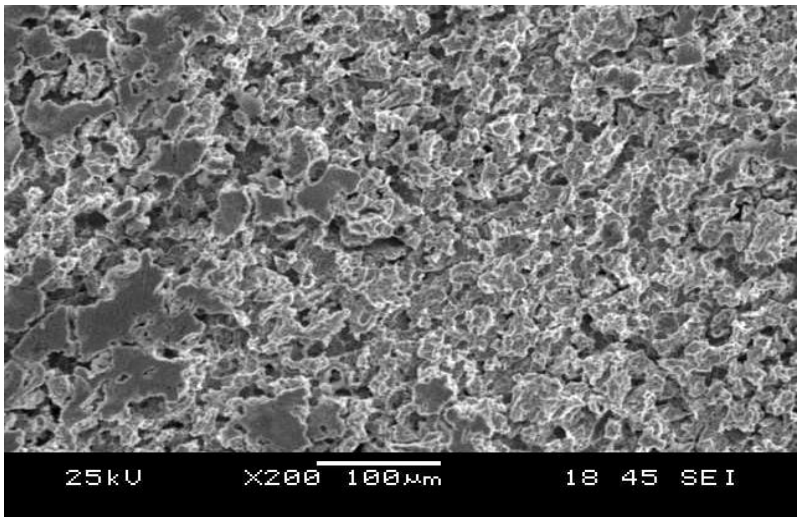

Fig 3.23 SEM Image of 409M (Normalized) after corrosion test

The SEM image of SS 409M (Normalized) after corrosion test is shown in Figure 3.23. Corrosion has been uniform throughout the surface.

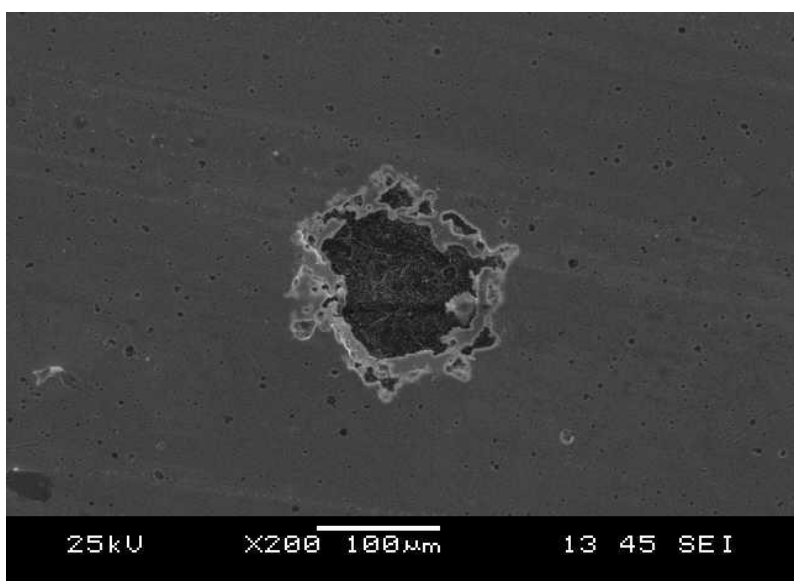

Fig 3.24 SEM Image of 430 after corrosion test

The SEM image of SS 430 is shown in Figure 3.24. We could see large pit formation andsurrounding the large pit many small pits are also seen.

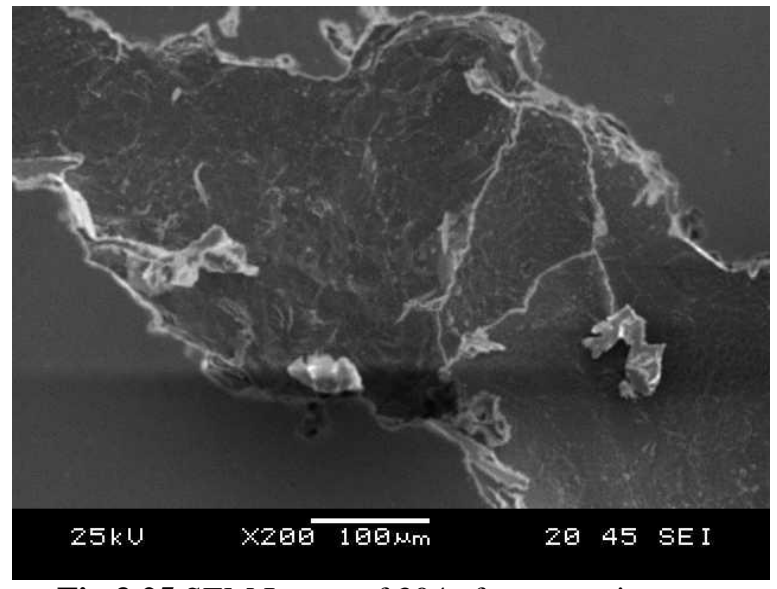

Fig 3.25 SEM Image of 304 after corrosion test

The SEM image of SS 304corrosion test is shown in Figure 3.25 , slight dissolutions on the surface can be seen.

\section{CONCLUSION}

The wear resistance of 409M has been studied using pin on disc machine and compared with Mild steel, SS 430 and SS 304. 409M has higher wear resistance than Mild steel and SS 430. It has lower wear resistance than SS 304. The wear mechanism could be oxidation wear. Since 409M find many structural applications, the corrosion behavior of $409 \mathrm{M}$ is studied using potentiostat. $409 \mathrm{M}$ has better corrosion resistance than mild steel and it has less corrosion resistance than SS 430 and SS 304. This is due to lower chromium content than SS 430 and SS304.

- The results show that increasing in sliding distance increase the wear volume for various loads $2 \mathrm{~kg}, 3 \mathrm{~kg}$, and $4 \mathrm{~kg}$. 409M in both annealed and normalized condition has lower wear volume loss than mild steel and SS 430 and this is in agreement with the earlier work.

- Increase in load increases the wear rate for various sliding distance $1570.80 \mathrm{~m}, \quad 2356.19 \mathrm{~m}$ and $3141.59 \mathrm{~m} .409 \mathrm{M}$ has lower rate than mild steel and SS 430 in both annealed and normalized condition.

- Wear resistance of $409 \mathrm{M}$ both in annealed and normalized condition show higher wear resistance than that of SS 430 and mild steel.

- As expected SS 304 has superior wear resistance than SS 409M, SS 430 and mild steel.

- SS 409M has excellent passivation than mild steel, thus it has high corrosion resistance than mild steel.

- $\quad$ SS 304 and SS 430 show more passivation region than SS 409M and mild steel and this is in agreement with the earlier work.

\section{REFERENCES}

[1] M.C.M. Farias, R.M. Souza, A. Sinatora, D.K. Tanaka, The influence of applied load, sliding velocity and martensitic transformation on the unlubricated sliding wear of austenitic stainless steels, Surface and coating technology; (2007) 9518-9523.

[2] Ram.Subbiah, Dr.R.Rajavel ,Dry Sliding Wear Behaviour Analysis Of Nitrided 316LN Grade Austenitic Stainless Steels Using Gas Nitriding Process".

[3] M. Aksoy, O. Yilmaz, M.H. Korkut "The effect of strong carbide-forming elements on the adhesive wear resistance of ferritic stainless steel". Wear; 2001; page no.639-646.

[4] J.D. Bressan, D.P. Daros, A. Sokolowski, R.A. Mesquita, C.A. Barbosa "Influence of hardness on the wear resistance of 17-4 PH stainless steel evaluated by the pin-on-disc testing". Materials processing; 2008; page no.353-359.

[5] C.X. Li, T. Bell "Sliding wear properties of active screen plasma nitrided 316 austenitic stainless steel".wear; 2004; page no.1114-11152.

[6] Lorella Ceschini, Giuseppe palombarini, Giuliano Sambogna, Donato Firrao, Graziano Ubertalli “ Friction and wear behavior of sintered steels submitted to sliding and abrasion tests". Tribology International; 2006; page no. 748-755. 
[7] D.J. Mills, R.D.Knusten "An investigation of the tribological behavior of a high-nitrogen $\mathrm{Cr}-\mathrm{Mn}$ austenitic stainless steel”. Wear; 215;page no. 83-90.

[8] A.M. Do Nascimento, V. Ocelik, M.C.F. Ierardi, J.Th.M. De Hosson "Wear resistance of WCp/Duplex stainless steel metal matrix composites layers prepared by laser melt injection". Surface and coating technology; 2008; page no.4758-4765.

[9] R.L. Liu, M.F. Yan "Improvement of wear and corrosion resistances of 17-4PH stainless steel by plasma nitrocarburizing". Materials and design; 2010; page no.2355-2359.

[10] H.Hanninen, J.Rom, R. Ilola, J. Tervo, A.Laitinen "Effects of processing and manufacturing of high nitrogen-containing stainless steels on their mechanical, corrosion and wear properties". Materials processing technology; 2001; page no. 424-430.

[11] M. Olzon-Dionysio, S.D. de Souza a, R.L.O. Basso b, S. de Souza "Application of Mossbauer spectroscopy to the study of corrosion resistance in $\mathrm{NaCl}$ solution of plasma nitrided AISI 316L stainless steel" Surface and coating; 2008;page no. 3607-3614

[12] Y.H. Yoo, J.H. Hong, J.G. Kim, H.Y. Lee, J.G. Han "Effect of $\mathrm{Si}$ addition to $\mathrm{CrN}$ coatings on the corrosion resistance of $\mathrm{CrN} /$ stainless steel coating/substrate system in a deaerated $3.5 \mathrm{wt} \%$ $\mathrm{NaCl}$ solution". Surface and coatings technology; 2007; page no.9518-9523.

[13] NaruemonSuwattananont, Roumiana S. Petrova, James L.Zunio,Daniel P. Schmidt "Surface Treatment with Boron for Corrosion Protection"

[14] Mehmet Acilar,FerhatGul "Effect of the applied load, sliding distance and oxidation on the dry sliding wear behaviour of $\mathrm{Al}-10 \mathrm{Si} / \mathrm{SiCp}$ composites produced by vacuum infiltration technique". Materials and Design; 2004;page no. 209-217

[15] Y.Shain "Wear behavior of aluminium alloy and its composites reinforced by $\mathrm{SiC}$ particles using statistical analysis". Material and Design; 2003; page no.95-103.

[16] S. Wilson,A.TAlpas “ Wear mechanism maps for metal matrix composites”. Wear; 1997; page no.4149.

[17] S. Das "Development Of Aluminium Alloy Composites for Engineering"Trans.Indian Inst. Met.; 2004, page no. 325-334.

[18] N. Natarajan,S. Vijayarangan ,I. Rajendran "Wear behaviour of A356/25SiCp aluminium matrix composites sliding against automobile friction material". Wear; 2006; page no.812-822

[19] Fontana. M.G., 1986, "Corrosion Engineering", McGraw Hill 